\title{
Human Resource Management In Saudi Arabia
}

Sunil Ramlall, Strategic HRM Consulting, LLC, USA

Hani Al-Amri, King AbdulAziz University, Saudi Arabia

Nadia Abdulghaffar, King AbdulAziz University, Saudi Arabia

\begin{abstract}
As companies seek ways to compete more effective, HR becoming more entrenched in business strategies, and comparative strategies are studied, this paper provides a comparison of HR practices in Saudi Arabia and the United States. Using the established literature on HR in the United States as a means to compare HR practices, the authors surveyed HR leaders in Saudi Arabia gathering highly valuable information. The results highlighted current practices and also where emphasis could be placed in aligning HR strategies to core business practices.
\end{abstract}

Keywords: HR in Saudi Arabia; International HR; Strategic HR; HRM; Management Strategies; Employee Training; Employee Selection; Human Resource Management

\section{INTRODUCTION}

s companies seek ways to compete more effective, HR becoming more entrenched in business strategies, and comparative strategies are studied, this paper provides a comparison of HR practices in Saudi Arabia and the United States. Using the established literature on HR in the United States as a means to compare HR practices, the authors surveyed HR leaders in Saudi Arabia gathering highly valuable information. The results highlighted current practices and also where emphasis could be placed in aligning HR strategies to core business practices.

There is a growing body of research showing that the methods used by an organization to manage its human resources can have a substantial impact on many organizationally relevant outcomes (Delery, 1998). Researchers and practitioners have long argued the case for human resource (HR) as a source of sustainable competitive advantages (Becker, Huselid, \& Ulrich, 2001; Benson, Young, \& Lawler III, 2006; Cascio, 2003).

The underlying assumption is that employees are unique and the skills would be difficult to imitate (Barney, 1991). While there are several studies that have shown some level of relationship between HR and firm performance (Bartel, 2004; Huselid, 1995), the studies remain to most extent predictive in nature. This paper builds on previous research by analyzing HR practices at Saudi Arabian firms to determine and analyze current HR practices and subsequently compare the results to established best HR practices.

\section{LITERATURE REVIEW}

Since the concept of HR emerged in the early 1980s, two basic paths of research have been developed in investigating the relationship between HR practices and organizational performance (Chand \& Katou, 2007). The first was based on the assumption that there is a direct relationship between individual HRM practices and/or internally consistent HRM systems of HRM practices, and organizational performance, e.g. (Arthur \& Boyles, 2007; M. A. Huselid, Jackson, \& Schuler, 1997; Jackson \& Schuler, 1995). The second was based on the assumption that there is an indirect relationship between individual HRM practices and/or HRM systems, and organizational performance e.g. (Belanger, Edwards, \& Wright, 1999; Ferris et al., 2007). 
The general consensus developed among researchers is that HRM practices and/or HRM systems do not lead directly to business performance (Katou \& Budhwar, 2006). Rather, HR practices influence firm resources, such as human capital, or employee behaviors, and it is these resources and behaviors that ultimately lead to performance (P. M. Wright et al., 2001). This implicit model assumes that there are variables that mediate a link between HRM practices and business performance(Chand \& Katou, 2007).

Martin-Alcazar, Romero-Fernandez, \& Sanchez (2008) argued that HRM is described as a field of research with three dimensions: sub-functional, strategic and international. The paper suggested that to "provide reliable explanations and valid responses to professional problems, HRM research must advance simultaneously in subfunctional, strategic and international dimensions" (p. 103). These authors concluded that the following areas still need to be addressed: (1) the strategic use of HR practices, (2) their international applicability, (3) global HR strategies and (4) the synergic integration of HR activities. This paper advances the literature in all of these areas.

Similar to previous empirical studies as listed among the 104 empirical studies cited in the Boselie, Dietz, \& Boon (2005) review of HR and performance research, nine investigate employee survey data in connection with a financial performance indicator. Wright, Gardner, \& Moynihan (2003) found that financial performance data from 50 branches within a large food services organization correlated .20 to .44 with questionnaire data collected in the branches prior to the period from which the financial performance data derive. For both commitment to the organization (an attitudinal measure) and the number of HR practices in use, sizeable correlations were found with financial performance.

Like other sound research in HR, the notion of strategic HRM is viewed as the HR practices that are theoretically or empirically related to overall organization performance. Although not all HR practices are strategic, there is growing consensus about which practices can be considered strategic (Delery \& Doty, 1996). These researchers utilized the theoretical works of Osterman (1987), Kerr and Slocum (1987), and Miles and Snow (1984), to identify seven practices that are consistently considered strategic HR practices. These are: internal career opportunities, formal training systems, appraisal measures, profit sharing, employment security, voice mechanisms, and job definition. Nearly all of these are also among Pfeffer's (1994) 16 most effective practices for managing people. In addition to Delery \& Doty's 16 questions on strategic HRM, Bartel's high performance model questions were also used to develop the survey instrument.

The questions used in this study were intended to determine the nature of HRM in Saudi Arabia. As Benson et al. (2006) found, high-involvement work practices are positively related to corporate financial performance. Tsai (2006) also found that the effective use of employee empowerment practices is positively related to organizational performance. Given that these studies were done in manufacturing and other industries, this research extends the literature to other industries and geographic locations.

\section{METHODOLOGY}

Bartel (2004) in the review of the literature on human resource management and organizational performance (Becker \& Gerhart, 1996; Delery, 1998) identified four methodological issues that researchers in this area need to consider: (1) the appropriate measure of organizational performance given the context of the study; (2) whether human resource management practices should be measured at the firm level or, instead, at the business unit or facility level; (3) possible omitted variables that could bias the estimated relationship between human resource management and organizational performance; and (4) the extent to which the estimated coefficients on the human resource variables can be interpreted as showing a causal relationship between human resource management and organizational performance.

For this proposed study, we collected information from various organizations measuring HR practices, and demographic questions. Factor analysis was performed to identify HRM systems, one-way ANOVA was be used to test the association of the demographic variables with organizational performance, and correlation analysis was used to test the relation among variables used in this study. 
The sample data study was focused on the field of human resources in Saudi Arabia, particularly human resources managers, and personnel managers and their assistants in a variety of Saudi organizations. A total number of 180 surveys were distributed to about fifty, randomly selected, Saudi companies. After collecting the questioners, 15 forms were excluded as they were incomplete, leaving us with a total number of 165 questionnaires to be analyzed using the SPSS program for statistics analysis. The survey questions are included in Table 1.0. and would be provided upon request.

The use of firm-level and establishment level surveys in industrial relations and human resources research became more common in the 1990s, especially because these surveys permitted large-sample analyses of questions associated with the connections between work practices, business strategy, and economic performance (Hunter and Pil 1995). The survey will utilize a combination of edited versions of theories by (Bartel, 2004; Delery \& Doty, 1996).

\section{Measures}

As HR positions itself as a strategic business partner, one of the most effective ways to do so is to support the strategic business goals through key performance indicators (Lockwood, 2006). Furthermore, with many HR functions increasingly being outsourced, credibility is earned through activities and outcomes that result in "deliverables" that promote and lead to organizational success (Ulrich \& Brockbank, 2005). The measures proposed to be used in this study have been rigorously tested as being critical in helping HR become a more effective business partner and function.

HR practices measures to be used in this study were taken from established literature on HR and firm performance such as (Bartel, 2004; Delery \& Doty, 1996). The first measure provides insights on managers' views on the company as a good place to work. Using a Likert scale, HR professionals will simply respond to a single question on how they viewed their employer as a place to work.

For example, the Hay Group found that the most admired companies had effective business practices in the following areas: organizational culture, strategy implementation, attraction and retention of talent, leadership development, fostering innovation, and performance management (HayGroup, 2005). The report also stated that successful companies assess performance by balancing profit measures with measures of shareholder value, customer satisfaction and employee satisfaction.

Employee selection practices will be analyzed to determine how practices vary at the respective organizations and the impact of these practices on firm performance. Holland, Sheehan, and De Cieri (2007) drawing from the resource based view of the firm argued that in an environment characterized by increasing levels of skilled labor shortages organizations need to design employment systems that prioritize human resource practices to enable competitive advantage.

Regardless of company size, industry or location, one factor is certain -- the war for talent has become fierce. The need for customized outsourcing has increased as business becomes more globalized and qualified candidates are harder to find. Never before has the importance of understanding best practices and solutions been more apparent and can often be the deciding factor in a deal (Workforce, 2008).

Employee training is typically used as a key HR practice. A recent meta-analysis by Tharenou et al (2007) suggested that "training is positively related to human resource outcomes and organizational performance but is only very weakly related to financial outcomes. The relationship between training and firm performance may be mediated by employee attitudes and human capital. Furthermore, training appears to be more strongly related to organizational outcomes when it is matched with key contextual factors such as organization capital intensity and business strategy, in support of the contingency perspective. "Further, training is independently related to organizational outcomes in support of the universalistic perspective of strategic human resource management rather than a configurational perspective" (p. 251). Similarly, Molina and Ortega (2003) found that higher training can have a positive effect on firm performance through factors such as employee satisfaction and customer loyalty. Overall, it is found that higher levels of training are associated with significant benefits which can increase firm value. 
In a study conducted by Schaubroeck, Shaw, Duffy, \& Mitra (2008) Pay-for-performance (PFP) perceptions were consistently related to personal reactions (e.g., pay raise happiness, pay-level satisfaction, and turnover intentions). Merit pay raises were strongly related to reactions only among employees with high raise expectations and high PFP perceptions. The interactive effects of under-met/over-met expectations and PFP perceptions were mediated by the extent to which participants saw the raise as generous and they were happy with the raises they received. Meisinger (2007) reiterated that corporate operations have come under increased scrutiny over the past years. Pay for senior executives, particularly CEOs, is often the focus of discussions about corporate excesses. Much of the debate is centered on pay for performance, especially since many poorly performing organizations have made huge, highly publicized payouts to executives.

Workplace Climate is the final HR practice measure. By identifying and facilitating organizational behaviors that lead to a more integrative work climate, an example of potential outcomes as documented by Peterson (2007) showed that retail organizations might reduce costs associated with turnover and that managers' perceptions of integration (connectedness or engagement with the organization) based on their organizational experiences and relationships significantly explained turnover. While formal and legal environments might be a good beginning (Schminke, Arnaud, \& Kuenzi, 2007) emphasis should also be placed on understanding the relationships among positive work climate, organization resources, employee's personality, organizational culture, and organizational citizenship behavior (Chien, 2004).

\section{RESULTS}

Researchers in the field of strategic human resource management (SHRM) have increasingly relied on the resource-based view of the firm to explain the role of human resource practices in firm performance (P. M. Wright, Dunford, B. B., \& Snell, S. A, 2001). Of no exception to Saudi Arabia is the need to be more competitive in the global economy. It is clear that forces have converged to support the idea of HR as more of a strategic partner (Lawler \& Mohrman, 2003). Corporations are undergoing dramatic changes with significant implications for how human resources are managed. We sought to identify key HR practices in Saudi Arabia and utilize existing literature to analyze these practices.

\section{Overall}

The descriptive statistics and correlation among key variables are provided. It must be noted that because multinationals are increasing in numbers in Saudi Arabia, there has been a development of western ways of managing human resources. However, there are still many factors that must be considered in managing human resources in Saudi Arabia. These factors include religion and culture (Mellahi \& Wood, 2001). So in analyzing the results, it must be viewed in the context that Saudi Arabia is experience a fair level of changes in developing and implementing HR practices. Table 2.0 will be provided upon request.

Participants in this study were highly educated with at least an undergraduate degree and in the process of earning their graduate degree or already have one. On average, they had more than seven years of professional HR experience and worked in a variety of industries.

Most of the participants felt that relevant strategies were being used to manage the workforce of their respective organizations. The mean score was 3.08 with one being least positive and 5 most positive. Similarly, they felt appropriate policies and practices are in place to manage and retain employees. The mean score was 3.04.

\section{Employee Selection}

The use of structured interviewing is rapidly increasing and is used by all sizes of organization. Behavioral interviewing is being used more than situational interviewing, and many respondents use both techniques. Structured techniques are most commonly used for management posts (Barclay, 1999). Employee selection continues to be a most critical responsibility of the HR function and any manager in an organization. A hiring mistake is sure to have a severe impact on the organization which is why such high emphasis placed on this responsibility. 
The mean score was 3.36. There were clear organizational structures given the score of 4.01. Job descriptions are used in the selection process to determine criteria for selection and identifying roles and responsibilities for the different positions.

Of deep significance, the study revealed that employees are not very involved in the decision making process. A mean score of 2.33 expresses the little input employees provide or have the opportunity to share their thoughts on any given employment related issue.

Interviews are used extensively during the selection process (3.37) and the use of tests is relatively prevalent (3.33). There is also a frequent use of hiring employees temporarily and them moving them to regular employees depending on performance and demand. When asked if effective policies are in place and used to attract candidates, respondents indicated through a mean score of 2.61 which is relatively low compared to the other scores.

\section{Training}

Rapid changes in technology and job design, along with the increasing importance of learning- and knowledge-based organizations, make training and development an increasingly important HR strategy (Noe, 2008). T\&D in Saudi takes a high priority according the results of this study. Employees are provided a new employee orientation and are provided opportunities to receive training on a fairly regular basis. Furthermore, participants indicated that the training focuses on improves one's knowledge with the intent to improve one's job performance.

\section{Pay for Performance and Performance Evaluation}

Compensation as defined by Geringer \& Frayne (1990) is the monetary and non-monetary, direct and indirect, that an organization exchanges for the contributions of its employees performance and personal contributions. In examining the national or regional models of compensation, national borders significantly define the contextual features such as national economic, demographic, and cultural conditions and must be considered when developing compensation systems that align with organizational, national, and regional strategies (Bloom \& Milkovich, 1999).

With scores of 2.97 for performance evaluated regularly and 2.52 for availability of advancement opportunities, there is clearly a lack of focus on pay for performance. The normal rewards for high performance are advancement in one's career and increased monetary rewards. Furthermore, the score for financial incentives was 2.52 which was one of the lowest scores for all responses.

\section{Climate}

There was a relative high emphasis placed on keeping secrets at work. Participants indicated a mean score of 3.05 for this question. Employees were relatively keen on performing their respective duties even though advancement opportunities were limited and there were not many at-risk financial incentives. It is clear that employees are taking pride in their respective roles and view their work as a commitment to their organization and possibly, a bigger cause as can be explained through the culture and religion. In general, employees found their respective organizations a good place to work.

\section{CONCLUSION AND DISCUSSION}

HR professionals in Saudi Arabia view HR as a core strategy for improving organizational performance. The results indicated mostly similar views on HR and current practices as compared to the United States and showed the willingness to utilize HR in a more integrated manner. Culture and religion provide strong explanation and guide for many of the workforce practices.

In today's global economy, understanding different workforce management practices is of deep importance to leaders and even politicians around the world. Doing business in Saudi Arabia, for example, would mean 
understanding the culture, religion, employment laws, etc. This research provided HR practices in Saudi Arabia thus providing critical information for academicians, students, business professionals and government officials.

While more emphasis could be placed on the selection process and measuring $T \& D$, etc. the general focus and need to align HR and firm strategies fit with existing literature. The areas that showed the most significant differences are explained through religion and culture.

\section{AUTHOR INFORMATION}

Dr. Sunil Ramlall is President of Strategic HRM Consulting, LLC. His Ph.D. is from the University of Minnesota. Prior to consulting, Dr. Ramlall taught at the University of St. Thomas and Hamline University in Minnesota. His research focuses on strategic HRM, international HR, HR metrics, positive organizational behavior, and relationships between HR and performance. He has published in journals such Journal of Applied Social Psychology, International Journal of Human Resource Development \& Management, Compensation \& Benefits Review, Journal of Human Resource Education, Applied HRM Research, and International Journal of Global Management Studies Quarterly. Dr. Ramlall's consulting firm (www.strategichrmconsulting.com) focuses on helping organizations develop and implement HR strategies to create sustainable competitive advantages, including creating strategic HR plans, HR metrics, compensation strategies, international HR, employee opinion surveys, and facilitation of OD interventions. E-mail: sramlall001@ gmail.com (Corresponding author)

Dr. Hani Alamri is an Associate Professor at the department of Business Administration, King Abdulaziz University. He received his Ph.D. from the University of Leicester, UK in Operations and Quality Management in 1995. His research focus is on production and operations management and total quality management. Dr. Alamri has been a consultant for more than 15 years in applying total quality management, (ISO 9000), performance measurement "Balance Scorecard." His research appeared in journals such as Scientific Journal of Management by Saudi Management Association, KSA., Arab Journal of Administration issued by Arab Administrative Development Organization (ARADO), and King Abdulaziz University Journal, Economics Administration. E-mail: halamri@kau.edu.sa

Dr. Nadia Abdulghaffar is an Assistant professor at the department of Business Administration, King Abdulaziz University. She received her Ph.D. from the University of Portsmouth, UK in Environmental Management in 2009. Her research focus is on environmental Management, solid waste management and strategic management. Dr. Abdulghaffar is a member of the Scientific Committee of the Centre for Development of Higher Education, Emergency and Crises Plan and the Quality of Teaching and Learning Committee. E-mail: nabdulghaffar@kau.edu.sa

\section{REFERENCES}

1. Arthur, J. B., \& Boyles, T. (2007). Validating the human resource system structure: A levels-based strategic HRM approach. Human Resource Management Review, 17(1), 77-92.

2. Barclay, J. (1999). Employee selection: a question of structure. Personnel Review, 28(1/2), 134-151.

3. Barney, J. (1991). Firm resources and competitive advantage. Journal of Management, 17, 99-120.

4. Bartel, A. P. (2004). Human Resource Management and Organizational Performance: Evidence from Retail Banking. Industrial \& Labor Relations Review, 57(2), 181-203.

5. Becker, B., \& Gerhart, B. (1996). Human resources and organizational performance: progress and prospects. Academy of Management Journal, 39(4), 779-801.

6. $\quad$ Becker, B., Huselid, M., \& Ulrich, D. (2001). The HR Scorecard: Linking People, Strategy, and Performance. Boston: Harvard Business School Press.

7. Belanger, J., Edwards, P., \& Wright, M. (1999). Best HR practice and the multinational company. Human Resource Management Journal, 9(3), 53-70.

8. Benson, G. S., Young, S. M., \& Lawler III, E. E. (2006). High-involvement work practices and analysts' forecasts of corporate earnings. Human Resource Management, 45(4), 519-537.

9. Bloom, M. C., \& Milkovich, G. T. (1999). A SHRM Perspective on International Compensation and Rewards. In Research in Personnel and Human Resource Management: JAI Press. 
10. Boselie, P., Dietz, G., \& Boon, C. (2005). Commonalities and contradictions in HRM and performance research. Human Resource Management Journal, 15(3), 67-94.

11. Boxall, P., \& Purcell, J. (2003). Strategy and Human Resource Management. Basingstoke, UK: Palgrave: Macmillan.

12. Cascio, W. (2003). Managing Human Resources: Productivity, Quality of Work Life, Profits (6th ed.). New York: McGraw-Hill Education.

13. Chand, M., \& Katou, A. A. (2007). The impact of HRM practices on organisational performance in the Indian hotel industry. Employee Relations, 29(6), 576-594.

14. Chien, M.-H. (2004). An Investigation of the Relationship of Organizational Structure, Employee's Personality and Organizational Citizenship Behaviors. Journal of American Academy of Business, Cambridge, 5(1/2), 428-431.

15. Delery, J. E. (1998). Issues of fit in strategic human resource management: Implications for research. Human Resource Management Review, 8(3), 289.

16. Delery, J. E., \& Doty, D. H. (1996). Modes of Theorizing in Strategic Human Resource Management: Tests of Universalistic, Contingency, and Configurations Performance Predictions. Academy of Management Journal, 39(4), 802-835.

17. Ferris, G. R., Perrew $\tilde{A} @$ C, P. L., Ranft, A. L., Zinko, R., Stoner, J. S., Brouer, R. L., et al. (2007). Human resources reputation and effectiveness. Human Resource Management Review, 17(2), 117-130.

18. Geringer, J. M., \& Frayne, C. A. (1990). Human resource management and international joint venture control: A parent company perspective. Management International Review, 30, 103-120.

19. HayGroup. (2005). What makes the most admired companies great? (February), 2-10.

20. Huselid. (1995). The impact of human resource management practices on turnover, productivity and corporate financial performance. Academy of Management, 38(3), 635-672.

21. Huselid, M. A., Jackson, S. E., \& Schuler, R. S. (1997). Technical and Strategic Human Resource Management Effectiveness as determinants of Firm Performance (Industry Overview No. 00014273): Academy of Management.

22. Ilies, R., Schwind, K. M., \& Heller, D. (2007). Employee well-being: A multilevel model linking work and nonwork domains. European Journal of Work \& Organizational Psychology, 16(3), 326-341.

23. Jackson, S. E., \& Schuler, R. S. (1995). Understanding human resource management in the context of organizations and their environments. Annual Review of Psychology, 46(1), 237.

24. Katou, A. A., \& Budhwar, P. S. (2006). Human resource management systems and organizational performance: a test of a mediating model in the Greek manufacturing context. International Journal of Human Resource Management, 17(7), 1223-1253.

25. Kerr, J., \& Slocum, J., John W. (1987). Managing Corporate Culture Through Reward Systems. Academy of Management Executive, 1(2), 99-107.

26. Lawler, E. E., \& Mohrman, S. A. (2003). HR as a Strategic Partner: What Does It Take to Make It Happen? Human Resource Planning, 26(3), 15-29.

27. Lockwood, N. R. (2006). Maximizing Human Capital: Demonstrating HR Value With Key Performance Indicators. HRMagazine, 51(9), 1-10.

28. Martin-Alcazar, F., Romero-Fernandez, P. M., \& Sanchez-Gardey, G. (2008). Human Resource Management as a Field of Research. British Journal of Management, 19(2), 103-119.

29. Meisinger, S. (2007). Pay-for-Performance Plans Should Be Fair and Clear. HRMagazine, 52(9), 10.

30. Mellahi, K., \& Wood, G. T. (2001). Human Resource Management in Saudi Arabia. In P. S. B. a. Y. A. Debrah (Ed.), uman Resource Management in Developing Countries. London: Routledge.

31. Miles, R. E., \& Snow, C. C. (1984). Designing strategic human resource systems, Organizational Dynamics (Vol. 31, pp. 36-52).

32. Molina, J. A., \& Ortega, R. (2003). Effects of employee training on the performance of North-American firms. Applied Economics Letters, 10(9), 549.

33. Noe, R. (2008). Employee Training and Development: MHHE.

34. Osterman, P. (1987). 'Turnover, employment security, and the performance of the firm'. In M. M. Kleiner (Ed.), Human Resources and Firm Performance B2 - Human Resources and Firm Performance. Washington, DC: BNA Press.

35. Peterson, S. L. (2007). Managerial turnover in US retail organizations. Journal of Management Development, 26(7/8), 770-789. 
36. Pfeffer, J. (1994). Competitive advantage through people - Competitive advantage through people. Cambridge: Harvard Business School Press.

37. Schaubroeck, J., Shaw, J. D., Duffy, M. K., \& Mitra, A. (2008). An Under-Met and Over-Met Expectations Model of Employee Reactions to Merit Raises. Journal of Applied Psychology, 93(2), 424-434.

38. Schminke, M., Arnaud, A., \& Kuenzi, M. (2007). The Power of Ethical Work Climates. Organizational Dynamics, 36(2), 171-186.

39. Tharenou, P., Saks, A. M., \& Moore, C. (2007). A review and critique of research on training and organizational-level outcomes. Human Resource Management Review, 17(3), 251-273.

40. Tsai, C.-J. (2006). High performance work systems and organizational performance: an empirical study of Taiwan's semiconductor design firms. International Journal of Human Resource Management, 17(9), 1512-1530.

41. Ulrich, D., \& Brockbank, W. (2005). The HR Value Proposition. Boston, Massachusetts: Harvard Business School Publishing.

42. Workforce. (2008). From 60 to 100 Watts--Increasing Your Recruiting Process Output. Workforce Management, 87(4), S4.

43. Wright, P. M., Dunford, B. B., \& Snell, S. A. (2001). Human resources and the resource-based view of the firm. Journal of Management, 27, 701-721.

44. Wright, P. M., Gardner, T. M., Moynihan, L. M., Park, H. J., Gerhart, B., \& Delery, J. E. (2001). Measurement Error in research on Human resources and Firm Performance: Additional Data and Suggestions for Future Research. Personnel Psychology, 54(4), 875-901. 